4CPS-083

AGING WITH HIV: OPTIMISING PHARMACOTHERAPY BEYOND INTERACTIONS

1J Gallardo-Anciano*, ${ }^{1} Y$ Gonzalez-Perez, ${ }^{1} \mathrm{ME}$ Calvo-Aragüete, ${ }^{2} \mathrm{JR}$ Blanco-Ramos. ${ }^{1}$ Hospital Universitario San Pedro, Hospital Pharmacy, Logroño, Spain; ${ }^{2}$ Hospital Universitario San Pedro, Department of Infectious Diseases, Logroño, Spain

10.1136/ejhpharm-2019-eahpconf.232

Background Pharmacotherapeutic complexity and potentially inappropriate medication (PIM) negatively affect therapeutic goals in HIV +adult patients and increase frailty and risk of falls. The POINT study carried out in Spain in 2017 alerted polypharmacy and pharmacotherapeutic complexity, and low adherence in HIV +adults.

Purpose To describe treatment complexity, fall-risk-increasing drugs (FRIDs) burden, and the presence of PIM in middleaged and elderly HIV + patients in our clinical setting.

Material and methods Observational, cross-sectional study was conducted in the referral hospital for HIV infection of our region in April 2018. We selected patients aged $\geq 45 \mathrm{y}$. Exclusion criteria: no medication information available in electronic clinical history. Age, gender and active chronic medication were collected. We calculated: overall treatment complexity and complexity due to concomitant one (MRCI-E tool); FRIDs with the most consistent association with a higher risk (antipsychotics, antidepressants, benzodiazepines, loop diuretics, opioids, antiepileptics and polypharmacy, according to the Systematic Review and Meta-Analysis of the EUGMS Task and Finish Group on FRIDs); anticholinergic drug burden (DBI score); and STOPP criteria. Polypharmacy was defined as $\geq 5$ medications. Fix-dose combinations were counted as one drug.

Results A total of 143 HIV +patients were included, all of them on antirretroviral treatment (ART), 92.3\% received concomitant non-HIV drugs (non-ART). Median age: 54y (SD 7.6; range 45 to $84 \mathrm{y}$ ) and $94(65.7 \%)$ male. Eighty-two patients $(57.3 \%)$ received $\geq 1$ FRID $(35.7 \% \geq 1$ benzodiazepine), $71(49.7 \%)$ had $\geq 1$ anticholinergic drug and at least one STOPP criteria was detected in 55 patients (38.4\%).

\begin{tabular}{llll} 
Abstract 4CPS-083 Table 1 & & & \\
\hline Pharmacological profile & $\mathrm{N}(\%)$ & Median (SD) & Range \\
\hline Total chronic drugs (ART+non ART) & 143 & $4(3.1)$ & $1-17$ \\
ART & $143(100 \%)$ & $2(0.9)$ & $1-5$ \\
Non-ART & $132(92.3 \%)$ & $3(2.8)$ & $1-14$ \\
$\geq 5$ non-ART & $40(28 \%)$ & $7(2.3)$ & $5-14$ \\
Overall complexity (ART+non ART) (points) & 143 & $8(7.1)$ & $2-38.5$ \\
ART complexity & 143 & $3(1.6)$ & $2-12.5$ \\
Non-ART complexity & 132 & $5(6.6)$ & $0.5-32$ \\
$\%$ non-ART complexity/overall & 132 & $63.6 \%(19.9)$ & $11.1 \%-94 \%$ \\
Number of FRIDs/patient & $82(57.3 \%)$ & $2(1.1)$ & $1-5$ \\
Benzodiazepine & $51(35.7 \%)$ & $1(0.4)$ & $1-2$ \\
Anticholinergic drug burden (DBI points) & $71(49.7 \%)$ & $0.75(0.7)$ & $0.2-3.46$ \\
High-risk DBI score ( $\geq 1)$ & $33(23.1 \%)$ & $1.58(0.5)$ & $1.05-3.46$ \\
Number of STOPP criteria & $55(38.5 \%)$ & $1(0.6)$ & $1-3$ \\
\hline
\end{tabular}

Conclusion The impact of non-HIV drugs on overall pharmacotherapeutic complexity, and the frequent use of PIM in patients $\geq 45$ y justifies the need for periodical reassessment of the treatment in order to optimise adequacy and benefit/risk balance.
REFERENCES AND/OR ACKNOWLEDGEMENTS

POINT study.

https://ejhp.bmj.com/content/25/Suppl_1/A249.2

No conflict of interest.

\section{CPS-084 EVOLUTION OF NONOCCUPATIONAL POSTEXPOSURE PROPHYLAXIS USE SINCE 2010 IN A THIRD-LEVEL HOSPITAL}

L Garcia*, FJ Bécares, MÁ Arias, C de Gorostiza, A Cordero, B Ardizone, E Tortajada. Hospital Universitario Fundación Jiménez Díaz, Hospital Pharmacy, Madrid, Spain

\subsection{6/ejhpharm-2019-eahpconf.233}

Background Nonoccupational postexposure prophylaxis (PEP) is a strategy to prevent new potential cases of human immunodeficiency virus (HIV) when primary prevention fails. However, it should never replace safe-sex practices.

Purpose We aimed to analyse the evolution in PEP use in our hospital in the past 8 years. Also, we wanted to evaluate its long-term efficacy in avoiding new HIV cases.

Material and methods We obtained data from our PEP dispensation register from 2010 to 2018, completing that with information concerning clinical history.

We checked if people on this register had antiretroviral dispensations for HIV treatment over these 8 years in order to detect new HIV cases among users of PEP.

Results We studied 1240 cases between 2010 and 2018 (92.6\% men, $7.4 \%$ women). The use of PEP grew in our hospital from 43 cases in 2010 to 317 cases in 2018.

Median age was consistent through the years and it was about 32-33 years' old. The main age group was that between 25 and 45 years' old $(75.02 \%$; constant through all the years $(67.86 \%-82.03 \%))$. However, the age range widened through the years, including people between 19 and 75 years in 2018.

Ninety-nine persons had received PEP in our hospital more than once in the past 8 years (between two and six times, being twice the more frequent case).

Among PEP users, 2.18\% contracted HIV at some time during the study period. Most of them got the infection much after their PEP dispensations. Five of them had been diagnosed in the basal analysis at the beginning of their PEP treatment, so they might have been previously infected. Only two cases were detected during the 6 months after PEP, so this could be a PEP failure. All of them had had unsafe sex.

Conclusion Despite PEP having shown efficacy in HIV prevention, people who misuse it and disparage safe sex, have the risk of long-term HIV infection in future episodes and, moreover, risk other sexual transmission infections.

Knowing the profile of PEP user and misuser (in our case young men about 33 years' old) can help pharmacists develop educational strategies focused on encouraging primary prevention.

\section{REFERENCE AND/OR ACKNOWLEDGEMENTS}

WHO. Risks of Unsafe Sex and AIDS. http://www.who.int/ whr/media_centre/factsheet1/en/

No conflict of interest. 